Article

\title{
Contemplative Media Studies
}

\section{Kevin Healey}

Department of Communication, University of New Hampshire, 20 Academic Way, Durham, NH 03824, USA; E-Mail: kevin.healey@unh.edu; Tel.: +1-603-862-3344

Academic Editor: Gregory Price Grieve

Received: 23 June 2015 / Accepted: 24 July 2015 / Published: 5 August 2015

\begin{abstract}
The psychological and socio-economic implications of digital technologies call for scholarship that engages questions about the nature of human consciousness, the construction of the self and the ethics of technical development. In this article, I outline a framework for an approach called contemplative media studies. This approach incorporates several different scholarly threads, namely: via critical political-economic media scholarship, a focus on achieving social and economic justice through policy initiatives and structural reform; via media and religious scholarship, an interest in the religious dimensions of digital culture and the role of media in shaping religious identity; and via contemplative studies, an appreciation of the applicability of contemplative principles to research methods and theory. This framework allows us to examine the spiritual ideology that drives the construction of commercial digital platforms and to ask whether alternative platforms might better catalyze human development. Anchored in a critical commitment to socio-economic justice, contemplative media studies is aimed at articulating an ethically-responsive and economically-sustainable architecture of human flourishing.
\end{abstract}

Keywords: contemplative studies; digital media; Silicon Valley; self

\section{Introduction}

On a wintry Boston morning in 2014, an ordained Zen Dharma teacher in the Korean Zen Taego Order stood before an attentive audience at the International Symposium of Contemplative Studies. Also an expert in organizational management, Ron Purser issued a critique of the appropriation of "mindfulness" practices by Silicon Valley companies like Google. He singled out for scrutiny the latter company's in-house guru, Chade-Meng Tan, whose Search Inside Yourself program has garnered widespread media 
attention. Much to Purser's surprise and delight, Tan walked into the room about half-way through the presentation. In a lively post-presentation conversation detailed elsewhere [1], Tan sparred politely with conference attendees and insisted that there is no fundamental tension between the pursuit of mindfulness and the pursuit of corporate profit. While his approach may have its shortcomings, he suggested, he was sure that Google was the best vehicle for his own deeply felt goal: to "democratize enlightenment" for all. Acknowledging some potential pitfalls, he ended the conversation with a simple request. Using colorful language to underscore his sincerity, he said, "Let me know if I fuck up."

In fact, Purser's ongoing work [2], as well as my own [3], is aimed precisely at calling into question Silicon Valley's idiosyncratic blend of free market libertarianism and spirituality. Drawing from McChesney's critique of digital capitalism, but engaging more substantively with its moral and religious dimensions, I have described this distinct set of beliefs about the nature of technology, markets and human virtue as the "catechism of Silicon Valley" [4]. Institutions like Facebook, Apple and Google have developed unique forms of spiritual practice, including "corporate mindfulness" programs, that conform to and enhance this over-arching ideology. As engineers of devices and platforms that reflect and shape the subjectivity of users, technology elites act as moral gatekeepers in a manner that is powerful, but often invisible. While technologies have never been morally neutral, digital media disrupt existing moral ecologies in new and pressing ways, and their commercial development often exacerbates existing social and political inequalities ([5], p. 198).

In this context, scholars of religion and popular media are charged with several important tasks. While it is important to understand how traditional religious communities construct identities within digital environments, we must also examine the spiritual ideology that drives the construction of such platforms in the first place and ask whether alternative platforms might better catalyze human development. Concerns about the impact of digital technologies on psychological and economic well-being call for scholarship that engages questions about the nature of human consciousness, the ethics of technical development and the construction of the self ${ }^{1}$.

As outlined here, contemplative media studies provides an integrated framework of theory and practice to address these tasks. I begin with a review of literature in media and religion. Here, I call for theoretical bridge-building with Christian theology and Buddhist philosophy and for deeper engagement with political-economic issues. I then outline contributions from the emerging field of contemplative studies, including its engagement with Buddhist concepts about the nature of the self and its emphasis on the benefits of contemplative practice for pedagogy and research. Following Jung's suggestion that such practices may yield "emancipation of the conscious from an illusionary conception of self" ([7], p. 13), the following sections outline the historical origins and contemporary dynamics of the conception of self embedded in the platforms of digital capitalism. The purpose of this approach is to employ contemplative insights to critique, and ultimately move beyond, assumptions about the self that drive contemporary digital culture. In other words, in response to Tan's colorfully-worded request, this approach suggests that Silicon Valley's techno-spiritual quest has been problematic all along. Yet,

1 Following Thompson [6], I understand the self as a constellation of images and narratives that an individual draws from and assembles in an ongoing manner in response to the question "Who am I?" Importantly, this approach suggests that the self is not a static object, but an active process. 
it rejects neither digital technology nor popular concepts like mindfulness. Instead, it offers a route for pursuing their development with greater integrity. Anchored in a critical commitment to socio-economic justice, contemplative media studies is aimed at articulating what I have called "an ethically responsive and economically sustainable architecture of human flourishing" ([5], p. 208).

\section{Bridge-Building in Media and Religious Scholarship}

Since the 1990s, media studies has suffered from a lack of research that integrates institutional critique with analysis of the mediated construction of religious identity. Religious belief and practice has fallen under the presumed territory of cultural studies, and audience-centered approaches have dominated the study of mediated religion. By contrast, political-economic approaches sometimes acknowledge the religious dimensions of market capitalism, but focus primarily on policy analysis.

In an effort to move away from the "media effects" approach that had dominated research on media and religion, Hoover [8] encouraged researchers to focus on religious adherents' interpretation and use of media "objects" in their practices. The decline of institutional religion and the subsequent rise of "quest" culture, he argued, had displaced the question of how media affects religious belief in favor of how individuals construct meaning through available media content. Interview-focused methods yielded a series of typologies that describe how individuals employ media in their quest for religious identity [8-10].

While moving beyond the media effects paradigm, such research over-emphasized audience reception, while neglecting structural and normative issues. Clark ([11], pp. 24-29) noted that the vision of "semiotic democracy" implicit in audience research overestimates consumer agency even as institutional constraints limit the range of available content. When it fails to acknowledge that audience activity is a moral domain in which the researcher herself is implicated, audience research becomes "limited to symbolic functions with an empty center" ([12], p. 171). Such research must "stake a claim on the ways the moral landscape is organized" in order to remain relevant ([12], p. 171). Yet, the descriptive nature of such research, and the assumption of traditional institutions' decline, tends to foster reluctance toward engagement with normative or theological questions. This reluctance is unfortunate since, as Clark (1998) noted early on, building bridges between cultural theory and theology could expand researchers' understanding of meaning-making by clarifying the categories that people employ in the process.

Bridge-building makes both pragmatic and theoretical sense. From a critical perspective, embracing the potentially "liberatory role of religion" [11] can move secular scholarship beyond antipathy toward religious belief that ultimately stifles opportunities for political solidarity ([13], p. 179). As West notes, his own approach to Marxist theory "neither requires a religious foundation nor entails a religious perspective," but is "compatible with certain religious outlooks" ([14], p. 233). To embrace such compatibility recuperates the productive alliance that Paul Tillich had forged with Max Horkheimer at the University of Frankfurt ([15], p. 27).

In fact, Simpson ([15], pp. 40-41) argues that the Christian tradition of "prophetic criticism" and the rational criticism of critical theory "depend upon each other", the latter providing concreteness and the former depth. When West ([16], p. 27) speaks critically against "the dogma of free-market fundamentalism", or when McChesney ([17], p. 23) describes the assumption of market infallibility as 
a "catechism", such concepts are more than merely metaphorical. They are instead contributions to a "theology of culture" that identifies the "faith" of a culture as idolatrous when centered on that which is not truly of ultimate concern [18]. Such analysis is crucial as the idols of technology and economic self-interest have come to define the culture of Silicon Valley [19].

Considering the pervasiveness of Buddhist and other East Asian ideas in Silicon Valley culture [3,20], theoretical bridge-building with these traditions likewise makes pragmatic and theoretical sense. Hubbard and Swanson ([21], p. 305) note that critical strains within academic scholarship and Buddhism both posit enlightenment as a "quest for liberation from ignorance and domination". Ironically, many of the same Silicon Valley companies espousing the benefits of mindfulness produce platforms and engage in business practices that entrench ideologies of ignorance and domination [22]. Yet, much critical scholarship, especially political-economic analysis, tends to focus on institutional and policy reform, while neglecting these subjective dimensions of political-economic reality. As Loy ([23], p. 404) suggests, institutional reform cannot hope to address human suffering in the long term if social actors are motivated primarily by the "three poisons" of greed, aggression and delusion ([23], p. 417). By offering a science and theory of ideology with politically liberatory potential, Buddhist concepts have much to offer critical scholarship [24]. For these reasons, I share Loy's ([23], p. 401) view that Buddhism's concern for personal transformation and the West's concern for social justice "need each other" if we are to address both individual and structural sources of suffering.

As I describe later, Silicon Valley's subculture is characterized by an idiosyncratic mixture of Christian apocalypticism, Gnosticism and evangelicalism, on the one hand, and East Asian concepts and practices, on the other. To appreciate the dynamics of the digital economy, it is incumbent upon scholars of media and religion to understand the history of these relationships and to engage more directly the theological and philosophical traditions from which technological elites have drawn in pursuit of their ambitious visions.

\section{Research on Buddhism and Digital Media}

While media and religious scholarship are beginning to integrate these threads, media analyses that directly engage normative and theological questions are predominantly Christian in orientation [25]. Meanwhile, secular institutional critiques, such as McChesney's, employ language that highlights the Protestant underpinnings of late capitalism while neglecting more recent non-Western influences. Scholarship that does engage Buddhism tends to reproduce an audience-centered, non-institutional approach. For example, Connelly [26] describes how Buddhist practitioners establish spaces for practice in digital environments like Second Life without asking whether Buddhist principles might call into question their commercialism or cognitive impact. In terms of broad institutional critique, some of the most exemplary analyses issued from a Buddhist perspective arise from outside of media studies altogether [27]. Current media and religious scholarship is weak in addressing institutional and political-economic issues in a way that engages and integrates Buddhist concepts.

Veidlinger [28] begins to fill this gap, but does so in a way that reproduces some of the problems of the media effects and audience studies research paradigms. The former approach often treated media and religion as separate entities, partly because the line between the two had not yet become thoroughly 
blurred. By arguing that the unique affordances of the Internet lead us to ask, "does the Internet make you Buddhist?" ([28], p. 133), Veidlinger implicitly frames the Internet as a separate and static entity. While it is true that the Internet, and social networking, "is likely to affect the spiritual development of humanity" ([28], p. 119), Veidlinger's conclusion is too deterministic and, similar to much audience studies research, does not adequately acknowledge the role of the political economy. For example, it may be true that the Internet's affordances have the potential to cultivate a critical orientation to the self that is suggestive of Buddhist principles of selflessness (anatman) and dependent origination (pratitya samutpada) ([28], p. 118). Yet, there is no guarantee that digital technologies will cultivate a Buddhist deconstruction of the self. In fact, I argue below that within the context of market capitalism, digital networks may foster the three "poisons" of greed, aggression and delusion ([23], p. 417). While the Internet had been founded on principles of openness and collaboration, Lessig shows that commercial development "is building an architecture that is quite the opposite of its architecture at its birth" ([29], p. 4). In other words, the Internet is not a separate, static entity, but one continually imbued with the values held by the engineers and developers steeped in Silicon Valley's techno-utopian subculture. To neglect the political-economic context of development is to fall prey to what Morozov calls "Internet-centrism": the assumption that there is a monolithic essence to "the Internet" instead of a complex of different real and potential networks with varying impacts on user subjectivity. Nevertheless, Veidlinger's positive vision is one worth pursuing through activism, policy reform efforts and alternative design.

Wagner and Accardo's [30] critical analysis of Buddhist apps is helpful in acknowledging potential incompatibilities between Buddhist principles and the construction of digital architectures. Like Veidlinger, the authors argue via medium theory that the construction of digital devices shapes religious practice and subjectivity. While acknowledging the possibility, in principle, of engaging the Dharma through appropriately-architected devices, they nevertheless question the extent to which Buddhist teachings can be realized via "a corporation-controlled device" ([30], p. 134). While rejecting a strict dualism between the online and offline worlds, they argue rightly that "it would be a mistake to assume that all engagement with virtual reality is the same" ([30], p. 139). The individualistic character of smartphone apps is especially problematic ([30], p. 140). The benefit of Wagner and Accardo's analysis is its recognition of how software and devices can shape religious practice and subjectivity through functional design, what the authors refer to as "procedural rhetoric" ([30], p. 140). As Lanier ([31], p. 6) notes, programmers "tinker with your philosophy by direct manipulation of your cognitive experience, not indirectly, through argument". Yet, while Wagner and Accardo suggest that some forms of procedural rhetoric may be better than others, they offer no specific alternatives to the corporate model ([30], p. 151).

\section{Contemplative Media Studies}

In light of these shortcomings, my research approach has two main goals. First, I wish to critique the role of design and political-economic constraints in shaping religious subjectivity and practice. In doing so, I aim to incorporate contemplative principles from Buddhism and other traditions in the manner that Cliff Christians [32] engages culturally-specific concepts in his development of a universalist ethics or in the manner that Wallis, Pepper and Steingass [24] integrate Buddhism and critical theory. 
Second, I aim to employ this contemplative framework not only to critique current technological architectures, but to offer alternative strategies for technological development. In this way, my approach builds upon scholarship in the emerging field of contemplative studies while adding a much-needed critical-institutional approach.

Building on three decades of medical and psychological lab research on contemplative practices, contemplative studies has expanded recently to include the application of contemplative principles in the areas of education, economics and music performance $[33,34]$. The field is supported by organizations, including the Center for Contemplative Mind in Society, the Association for Contemplative Mind in Higher Education and the Contemplative Studies Initiative at Brown University. Drawing from a range of religious traditions and newer fields, like neuro-phenomenology and positive psychology, this approach aims at "cultivating individual and collective forms of enhanced intelligence, wisdom and well-being" among students, scholars and citizens ([35], p. 4). Much of this work focuses on "mindfulness". As such, it is indebted to Jon Kabat-Zinn ([36], p. 4), whose definition of "mindfulness" as "paying attention in a particular way: on purpose, in the present moment, and non-judgmentally," is still widely cited ([37], p. 269).

Though contemplative scholarship has expanded beyond the lab, it is still focused largely on individual experience, emphasizing the acceptance of one's thoughts, feelings and sensations ([38], p. 232). This individualist focus tends to neglect the ethical frameworks from which Buddhist and other contemplative practices stem, leading to a potential "denaturing" of concepts like mindfulness ([39], pp. 11-13). Such decontextualized applications limit the ability of scholars to address the institutional and systemic context of human suffering. The question of how to preserve the "integrity of practice" has thus served as a key point of contention, and some practitioner-critics describe misappropriation in corporate or military contexts as "a kind of asset stripping" that amounts to "taking the fruit while killing the root" [40].

With such concerns in mind, scholars have begun to articulate an intersubjective analysis that acknowledges "a collective, field aspect of consciousness" ([35], p. 9). This development has implications for critical media and political-economic scholarship. For example, contemplative practices are demonstrably effective in uprooting habitual thought patterns and cultivating selfless action within the individual ([6], p. 72). Such personal impacts would find their collective parallel in revitalized media institutions that disrupt, rather than enable, dominant ideologies that entrench socio-economic inequality. Along these lines, Purser [27] and I [22] have employed contemplative principles to critique business organizations and media industries. In this way, my approach differs from Wilson ([41], p. 11), whose history of mindfulness brackets the question of whether mindfulness "works". I proceed on the assumption that mindfulness practices do "work", albeit with different impacts depending on intent and application. Some reinforce inequitable power structures; some challenge them. Some applications are better than others.

It is worth noting that there is substantial scholarly debate regarding whether, and to what extent, Buddhist philosophy and mindfulness practices include an ethical or moral component with socio-political implications [2]. Some argue that Buddha had always intended to provoke leaders and initiate a broad social movement [42]. Arguing on behalf of "socially engaged" or "critical" Buddhism, Brazier ([43], p. 35) argues that "the Buddha was strident in his criticism of the religious, social, and 
personal mores of his day, 2000 years before Luther". By contrast, Loy ([23], pp. 403-4) argues that there is no clear parallel within Buddhism to the type of prophetic social critique within Jewish and Christian traditions. Nevertheless, he argues that contemporary Buddhists "have a much better understanding of the structural causes of $d u k k h a$ " and, therefore, must "develop more freely the social implications of its basic perspective".

While such debates about what constitutes authentic Buddhist practice are important, it is not imperative to resolve them here, since, like the broader field of contemplative studies, the approach I outline does not claim to be Buddhist per se. Instead it seeks points of resonance between traditional contemplative principles and the long-standing commitment of critical media scholarship to addressing issues of political-economic justice. Broadly speaking, the term "contemplative" suggests an "an inward or first-person focus that creates opportunities for greater connection and insight" ([33], p. 5). Importantly, as the practitioner learns to "connect his or her inner world to the outer world" ([33], p. 6), a contemplative approach has the impact of creating "a more just, compassionate, and reflective society" ([33], p. xii). While I draw from specific Buddhist principles, such as avidyā and annatā, in the sections that follow, broadly speaking, the term "contemplative principles" refers to "seeing things as they are, being open to new ideas, appreciating the contribution of silence to learning, valuing each human voice, [and] honoring the constantly changing nature of ideas" ([33], p. 91).

I have defined contemplative media studies as "the application of contemplative practices and principles to the critical analysis of media technologies, content, and institutions" [44]. Here are some questions in each category:

Technologies:

- How does the architecture of digital platforms impact the formation of self-identity?

- How can contemplative principles inform the design of such platforms so that they might enhance our attention and focus, rather than serving as sources of distraction and self-absorption?

\section{Content:}

- Does news coverage adequately engage the moral and spiritual dimensions of the Silicon Valley subculture?

- Does the sexualization of yoga in popular magazines undermine the socially-transformative aspects of contemplative practice?

Institutions:

- How do the dynamics of the digital economy impact socio-economic issues, such as gentrification and income inequality?

- What alternative institutional and economic structures might better enhance collective wisdom and compassion while alleviating suffering?

In this article, I will focus mainly on questions related to technologies and institutions. In addressing such questions, a contemplative approach seeks to "examine media as intellectual technologies, critiquing the impact of digital power structures on the formation of self-identity and the perception of reality, while providing a moral compass for the development of 'normative technologies' built upon 
values of justice, stewardship, and openness" [22]. Contemplative media studies therefore incorporates several different scholarly threads, namely: via critical political-economic media scholarship, a focus on achieving social and economic justice through policy initiatives and structural reform; via media and religious scholarship, an interest in the religious dimensions of digital culture and the role of media in shaping religious identity; and via contemplative studies, an appreciation for the applicability of contemplative principles to research methods and theory.

As a means to facilitate innovative theoretical insight and provide ethical grounding for critique, contemplative practice is an important part of the research process. As Maslow ([45], p. xvi) noted, "knowledge of one's own deep nature is also simultaneously knowledge of human nature in general". Practice may involve, but does not require, identification with a particular tradition ([33], p. 21). For example, silent, solitary observation of the natural environment can catalyze a transcendental consciousness with implications for the study of media ecology [46,47]. Other practices include meditation, introspection, yoga, T'ai chi ch'uan, deep listening and music improvisation. The goal is active cultivation of contemplative wisdom, which Thompson ([6], p. 78) defines as "the kind of knowledge and experience belonging to traditions that use practices of calming and focusing the mind and body in order to bring about human transformation according to a vision of a harmonious and benevolent life". In its concern for human suffering, such wisdom contains a normative element similar to that of Christians's ([48], p. 442) notion of "human flourishing”, or Maslow's ([45], pp. 28-30) vision of "full humanness".

Contemplative practices cannot replace, but can greatly enhance, conventional research methods, especially critical, qualitative and interpretive approaches ([33], pp. 183-84; [49]). Contemplative practice lends itself to critical, qualitative inquiry that rejects the assumption of moral neutrality in research, an assumption that often yields complicity with the socio-economic status quo. Yet, it enables the researcher to avoid the pitfall of cynicism within a critical research program. Barbezat and Bush ([33], p. 29) show how practices aimed at fostering empathy and compassion can cultivate the human capacities for cooperation and connection that are increasingly important as we face complex global issues, like economic inequality and climate change. Such practices help individuals move beyond "habitual modes of engaging with injustice and suffering", creating opportunities for renewed engagement ([33], p. 183). For example, in his course on Meditation and Media Violence at the University of California, Davis, Alan Klima found that compassion meditation helped his students move beyond the disempowering view of mass media as merely a source of compassion fatigue ([33], p. 184). Students were able to view familiar scenes of violence in a different, ethically-engaged manner that opened up possibilities for "making change in the world" (quoted in [33], p. 184). This pedagogical insight applies equally to critical research programs: if scholars wish to articulate the contours of broad-scale institutions premised not on greed and delusion, but collective wisdom, such researchers must first know how to cultivate and maintain compassion, empathy and mindfulness within themselves.

In this sense, contemplative media studies is similar in intent to the "positive ethical science" of humanistic psychology, which holds as its aim the achievement of both personal and collective integrity ([50], p. 135). The personal and collective are intertwined since integrity involves "a willing sensitivity to the needs of the whole, an ethic that combines caring for others in the world with a sense of justice in insisting that others treat us and we treat them as we would all like to be treated ([51], p. 12). 
Of course, a commitment to stand by one's convictions can veer toward arrogance and fanaticism when it fails to properly acknowledge the concerns and judgments of others ([52], pp. 259-60). In the following sections, I suggest that this tendency toward arrogance and fanaticism has come to characterize the techno-utopianism of Silicon Valley. I turn first to the historical development of this ideology and then to its impact on the emerging digital economy.

\section{The Catechism of Silicon Valley}

In defense of Facebook's controversial privacy policy changes in 2011, Mark Zuckerberg insisted that the company would not be "trapped" by convention, but instead would "always keep a beginner's mind" with regard to its business practices [53]. His use of the phrase "beginner's mind," which reflects the deep-rooted commingling of Zen Buddhism and American corporate culture ([54], pp. 104-6), is ironic. While the phrase suggests a willingness to recognize and uproot habitual patterns of thought regardless of their nature, in a corporate context, it carries an implicit restriction: effective leaders cultivate a beginner's mind only with regard to conventions that limit growth and productivity, never with regard to market ideology itself. Despite Zuckerberg's suggestion, appropriation of the philosophies of East Asia by Silicon Valley has added rhetorical flair and an air of authentic counter-culture legitimacy to an otherwise conventional political-economic status quo. As the following section shows, this status quo exacerbates existing economic inequality and treats human suffering as a market externality. Viable alternatives, as exemplified by the worker-owned Mondragón Cooperative Corporation in Spain, which produces computer chips and other high-tech machinery, are beginning to garner attention, but are largely ignored [55]. While the "catechism" of market capitalism is not new to the digital economy [17], it is more firmly entrenched as the view of digital technologies as sacred objects permeates elite circles and the culture at large [19].

What McChesney ([56], p. 67) described in the late 1990s as "the advent of free market theology as reigning civic religion" represents the culmination of long-standing tensions in American religious history. In the pre-Revolutionary colonies, itinerant preacher George Whitefield embraced the communications techniques of a burgeoning consumer marketplace, defending his work as "trafficking for the Lord" ([57], p. 128). Whitefield's itinerancy contributed to a political revolution that also gave birth to a new religious economy based on a consumerist model of religious engagement. Drawing from Adam Smith, the Founders posited disestablishment as a spur for religious competition that would whittle away error to reveal a "pure and rational religion" ([58], p. 315). Competition arose, but so did an unforeseen concentration of wealth and power. Tribes that succeeded in the religious marketplace did so by acquiescing to the political-economic status quo and muting their prophetic voice. Fundamentalists abandoned the commitment to social action that had characterized the work of earlier evangelicals ([59], p. 92), while the Social Gospel movement aimed to redeem market capitalism from within [60]. In the emerging medium of radio broadcasting, progressives and conservatives alike refrained from social critique in favor of commercial palatability [61].

By 1929, John Dewey ([62], p. 5) noted, "we are living in a money culture. Its cult and rites dominate". Advertising and public relations assumed immense institutional power, with Ivy Lee describing PR as "the secret religion of all religions" ([63], p. 132). In response to the public's distaste 
for direct corporate propaganda, in the 1950s, business elites actively recruited religious leaders to mobilize against the New Deal and to preach the gospel of free enterprise. With corporate support, preachers, like the Rev. James Fifield, created a convincing public relations campaign for corporate America, articulating theological arguments for the compatibility of Christianity and capitalism ([64], pp. 15-18). As Ewen ([63], p. 246) notes, FDR's programs "went head-to-head with the religion of private enterprise". As commercial imperatives select winners and losers in the religious economy, success is enjoyed by those versions of Christianity that comport with market ideology.

In the latter half of the twentieth century, the decline of institutional religion led to a business-minded religion industry and a consumer-oriented "spiritual marketplace" focused on the quest for spiritual identity through media and retail products [9]. Among conservatives, traditional denominational structures gave way to networks of para-church organizations and business-like megachurches that became deeply involved in Washington politics. Among progressives, changes in immigration policies led to an increased interest in East Asian philosophies ([9], p. 73). The counter-culture found compatibility between meditative practice, psychedelic experimentation and the anti-hierarchical potential of computerized information processing systems. Psychedelic evangelist Timothy Leary and Grateful Dead lyricist John Perry Barlow were among the first proponents of cyberspace as a consciousness-expanding technology. Steve Jobs followed a similar path, drawing from Zen meditation, Hindu practices and psychedelic experimentation to build the cult-status branding of Apple's digital products ([20], pp. 86-87).

Rejecting traditional forms of political activism ([65], p. 35), these counter-culture leaders assumed that "the revolutionary nature of the technology could trump the monopolizing force of the market" ([17], p. 105). The surprising resonance between progressive and conservative ideologies culminated in the mid-1990s passage of the Telecommunications Act of 1996, which represents the joint effort of technology elites, like Esther Dyson, and religious conservatives, like Newt Gingrich ([17], p. 105), who described the policy as part of a divinely-inspired "mission" (quoted in [65], p. 231). Far from up-ending the political-economic status quo, the Telecom Act had instead solidified the cultural and economic power of religious conservatives and Silicon Valley entrepreneurs.

Tech leaders have thus come to play a role mirroring that of George Whitefield centuries before. While Whitefield appropriated the tools of the marketplace to "ply a religious trade in the open air of the marketplace" ([66], p. xviii), techno-utopians, like Ray Kurzweil, act as secular evangelicals on behalf of what some have called "the Gospel of "Singularity"' [67]. This vision, which clearly echoes Christian Gnostic and apocalyptic themes [68], posits a near future in which human beings and computers converge. For critics like Jaron Lanier ([31], p. 25), Kurzweil's vision of immortality through technology represents a kind of "rapture" for nerds. As techno-utopianism posits digital networks as the source of human salvation, technical activity represents an attempt to overpower death ([32], p. 69). This goal resonates with the ambitious mission of Silicon Valley's most successful enterprises. In 2012, Google hired Kurzweil to further its vision of artificially-intelligent systems that might, in the words of co-founder Sergey Brin, "be like the Mind of God" (quoted in [69]).

Just as market-friendly forms of Christianity succeeded in the twentieth century, certain forms of East Asian philosophy and practice find a home in Silicon Valley to the extent that they are compatible with the long-standing "catechism" of market ideology. Once-idealistic counter-cultural leaders have largely 
abandoned the anti-commercial ethos of early Internet culture, and the emergence of programs, such as Wisdom 2.0, represent consumer-friendly appropriations of Buddhist principles that grease the wheels of corporate capital, while failing to embody the principles of "right mindfulness" [3]. Even Chade-Meng Tan, Google's in-house mindfulness guru, admits that his Search Inside Yourself program succeeds in reducing personal stress, but falls short in terms of generating compassion [1].

As McChesney ([17], p. 28) suggests, the "unforgiving logic" of the market requires managers to "internalize the necessary values" for success. In Buddhist terms, Loy ([23], p. 419) suggests that "the system has attained not only a life of its own but its own cetan $\bar{a}$ volitions, quite apart from the motivations of the individuals who work for it and who will be replaced if they do not serve that institutional motivation". Over time, institutional selectivity has yielded a complex ideology, unique to Silicon Valley, but globally influential, that incorporates secular, East Asian and Christian ideas. Drawing from McChesney's critique of digital capitalism, I have referred to this ideology as the "catechism of Silicon Valley" [4]. In my view, the charge of media and religious scholarship is to critically interrogate this ideology. To that end, I have outlined a set of "proverbs" $[4,70]$ that call into question its basic assumptions, as follows:

- Information is not wisdom;

- Convergence is not integrity;

- Transparency is not authenticity;

- Processing is not judgment;

- Storage is not memory;

- Connectivity is not intimacy.

These are some of the key distinctions that the catechism of Silicon Valley seeks to obscure. To the extent that it elides these distinctions and equates technological prowess with human virtue, it encourages specific forms of subjectivity among elites and users (constructions of the self) that undermine the achievement of individual and collective integrity. Ironically, this catechism represents precisely the type of fanaticism and hubris that the Founders had sought to avoid in their arguments on behalf of religious disestablishment.

\section{Architectures of Contempt}

The catechism of Silicon Valley holds markets and technologies as sacrosanct, outside the bounds of legitimate critique. Proponents view digital technologies as benign and morally neutral or, more often, as uniquely capable of cultivating the human virtue [4]. This view is bolstered by rhetoric that displaces human agency and responsibility, even as elites shape its development and use. This problem is not new, but endemic to capitalism. Prior to computer systems, consumer surveillance took the form of credit ratings, which represented a form of "moral accounting" enacted by elites and internalized by citizen-consumers [71]. Computerized automation does not remove this aspect of moral judgment; yet, its air of scientific objectivity and technological efficiency helps to obscure processes of moral gatekeeping.

Drawing from Veidlinger ([28], p. 121), I suggest that the Buddhist principle of dependent origination, which holds that nothing "can be truly separated from the conditions that give rise to it", calls into 
question the assumption of technology's moral neutrality. In this sense, the view of technology as morally neutral is both a manifestation and cause of avidyā: an ignorance about the nature of the self and reality that generates a habit of "not looking" at the consequences of our actions ([43], p. 9). From a contemplative perspective, corporate ideology enables a form of collective delusion whose socio-economic impacts are unevenly distributed.

In the digital economy, as in previous eras, business practices function as rituals that solidify privileged forms of subjectivity (constructions of the self) among elites and industry insiders. Silicon Valley subculture is exclusive in terms of gender, race, age and socio-economic status. Boards of directors, employees and conference attendees are overwhelmingly white and male. Ageism is rampant, and tech culture has long been characterized by "a belief that the young were agents of salvation" [72]. In San Francisco, attacks on techies wearing Google Glass and protests against employees riding Google buses are manifestations of growing class tensions. This lack of diversity among developers and executives leads to a skewed vision of what products and solutions are important. The digital economy reflects the interests of the privileged self.

While conferences like Wisdom 2.0 tout the professional benefits of "mindfulness" practices, this ethos of privilege and entitlement selects for individuals who demonstrate an attitude of contempt, rather than compassion, toward employees and users. Critics were quick to condemn the dismissive way that Google panelists responded to protests at Wisdom 2.0 where members of the East Bay Meditation Center in Oakland had sought to draw attention to the problems of gentrification in San Francisco [3]. Anecdotes abound illustrating the contemptuous attitudes of tech elites. Despite his personal interest in Buddhist and Hindu practices ([20], p. 87), Steve Jobs famously described fellow employees as "shitheads". In a message to users in which he openly admitted and celebrated his site's user data experimentation, OKCupid's Christian Rudder included an illustration of a guinea pig on which he had scrawled the label "you". Mark Zuckerberg once referred to Harvard students as "dumb fucks" for trusting him with e-mails, photos and addresses [73]. Such comments belie the more eloquent "beginner's mind" rhetoric he later adopted to justify Facebook's wholesale decision that sharing and openness "would be the social norms now".

Such anecdotes indicate not that a few individuals have single-handedly shaped the digital economy to reflect their personal vices, but rather that, to the extent that it has been commercialized, the ethos of contempt is endemic to the digital economy itself. The personal character of those who achieve success reflects that underlying dynamic, yet most employees and users are unaware of its broader socio-economic impacts, because they are indirect and manifest most intensely in underprivileged, hence invisible, communities at home and abroad. While tech employees in Silicon Valley benefit from on-site yoga classes and meditation rooms, the walls of Apple's factories in China are adorned with such quotations from Foxconn CEO Terry Gou as "Growth, thy name is suffering" and "A harsh environment is a good thing" ([74], p. 89). As U.S.-based leaders internalize market values, they tend to ignore or refuse responsibility for labor conditions at home and overseas; the environmental impact of e-waste; the use of commercial platforms to enable human trafficking; the impact of revenge porn on young women; and other market externalities ([17], p. 28).

Users, whose data comprises the lifeblood of the information economy, are held in contempt by commercial imperatives that require managers and developers to treat them as a means to an end. Legal 
and rhetorical strategies for nudging users toward greater personal transparency amount to a process of soft coercion ([5], p. 200). The collective implications of this process are emerging. Data aggregation exacerbates socio-economic inequality as insurance companies, credit card companies and retailers engage in price discrimination and the marketing of predatory financial instruments. Marketers divide users into class-based reputation categories that, over time, can become self-fulfilling prophesies [3]. Among users themselves, the affordances of commercial platforms feed into a "worldview premised not on hospitality but on exclusion, ostracization, maliciousness, and vengeance" [75]. Harassment and bullying have caused legal headaches for companies that had initially enjoyed financial support from investors.

This is the broader political-economic context that Veidlinger [28] overlooks in his more celebratory analysis of digital platforms. By contrast, Loy ([23], p. 417, emphasis original) notes that "we have much more powerful institutions than in the time of the Buddha, in which collective selves often assume a life of their own, in the sense that such institutions have their own motivations built into them". The three "poisons" of greed, aggression and delusion can impact not just our individual selves, but our collective selves, as well ([23], p. 417). As an ideology that is often articulated by elites, but broadly internalized by employees and users, the catechism of Silicon Valley confirms the premise that ignorance, witting or unwitting, is the source of both personal and collective suffering.

\section{Coded Mirrors}

The problem with ongoing attempts to critique the digital economy is two-fold: "Those that know technology cannot see beyond it, and those that don't know the technology cannot see into it" [76]. Indeed, commercial digital platforms operate as a one-way mirror, both transparent and reflective ([5], p. 198). User behavior is transparent to a privileged self positioned behind the dark veil of proprietary code, which "gives some but not others the power to watch" ([29], p. 92). It is a powerful, but limited gaze: developers assume the ultimate importance of user data, but cannot, or will not, "see beyond it" to recognize the ill-effects of data collection and broader market externalities. The platform interface, brighter by virtue of its public character appears to reflect the user's image back to herself. Yet, it obscures the operations of developers, whose values drive the platform's architecture and shape users' constructions of the self.

A social media platform is a "tool for self-formation", and the use of Facebook and other such sites constitutes a "technique of self" [77]. While popular discourse assumes that such technologies are morally neutral, it is clear that technologists construct platforms in ways that reflect their identity and values. The misogyny and lack of diversity in video games is a simple example. More importantly, digital architectures encode specific assumptions about the self. While they cannot exert complete control over users' self-formation, digital platforms persuade users through choice architecture and procedural rhetoric ([30], p. 140). Especially as digital networks tend to yield monopolies, developers can have tremendous influence on cultural subjectivity, directing attention and shaping consciousness in powerful ways.

As Metzinger argues, lab experiments demonstrate the relative ease with which researchers can employ virtual reality technologies to manipulate subjects' internal self-models, including the perceived 
location of their body in space. Veidlinger ([28], p. 127) correctly infers that online identities can likewise "trick the mind into perceiving that one's identity extends into the cyberworld", and that this effect would increase over time. However, while this affordance has the potential to "make one think more critically about what exactly the individual self is" ([28], p. 127), in the context of digital capitalism, it tends instead to entrench an unreflective notion of the self. For example, Shatzer ([78], p. 21) notes that the success of Second Life depends partly on how it "sells the American Dream to those struggling to find utopia in real life". Users may come to prefer the hyper-real identities they build in such platforms, a preference that ultimately benefits platform owners and marketers. In this sense, such spaces create a "fantasy desire that supports an exploitative reality" ([54], pp. 107-8).

To be clear, I am not arguing for a dualism that posits an authentic offline world against an inauthentic online world; instead, I am suggesting that some digital architectures afford a more reflective relationship to the self than others. Ideally, such architectures might facilitate the realization of anattā or "not-self", a principle holding that the ordinary perception of one's self as a stable entity, while psychologically and socially useful, is ultimately illusory ([23], p. 415). A consumerist economy undermines this realization, however, by actively exploiting and aggravating the sense of "lack" that accompanies the illusory nature of the self. As Loy ([23], pp. 416-19) explains, "the system generates profits by perpetuating our discontent in a way that leaves us always wanting more", thereby reinforcing "the personal dukkha built into the delusions of consumerism".

Moreover, while the "realization of selflessness" would entail that "the person is no longer fixed or overinvested in self-images" ([27], p. 19), the user's fixation on self-image, and the platform's surveillance and quantification of that self-image, is precisely the goal of commercial social media [3]. Users who score high in measures of narcissism are especially susceptible to this dynamic and tend to use social media as "a technologically enhanced mirror" ([79], p. 2010). Average users similarly engage in what Purser ([27], p. 21) calls "reality projects", which consist of the "symbolic ways we try to make ourselves real in the world". This process is thoroughly commodified, as both users and platform developers assess online communication in advertising terms. For a nominal fee, Facebook's "Promote" feature allows users to purchase prominence on their friends' News Feed. By shaping their communication to conform to the logic of advertising discourse, users relate to the self as a valuable market commodity rather than a necessary illusion. This process finds its logical conclusion in the "self-exploitation" of adolescents whose social media use reflects a deep tension between the struggle for social agency and the pressures of a highly-sexualized commercial media environment ([80], p. 106).

Tasked with the extraction of revenue from commercial technologies of the self, developers assume the role of moral gatekeepers. Executives offer sweeping, self-interested statements on the ethics of privacy and information. A primary tenet of the catechism of Silicon Valley is the notion that in cyberspace, transparency with regard to one's personal life is a measure of one's authenticity [4]. Facebook's aforementioned changes to its privacy policies proceeded from this assumption, yet it is contradicted by sociological research indicating that an individual's control over the relative openness of one's personal boundaries is central to the achievement of autonomy and authenticity ([81], p. 62). In other words, authenticity actually requires some measure of privacy. Of course, elite pronouncements are not so much descriptive as prescriptive: their intent is to actively shape user behavior, subjectivity and social norms in ways that support their business models. 
The moral-gatekeeping role of tech developers extends even to simple choices about interface design: Mark Zuckerberg once commented that he disapproved of a "dislike" button because it would not be "good for the world" [82]. More importantly, moral-technical gatekeepers formulate and encode broad ethical policies about the construction of self. Facebook's "real name" policy, which requires profile names to reflect users" "authentic identity", sparked intense debate among users and scholars. "You have one identity", Zuckerberg pronounced in 2010, adding that "having two identities for yourself is an example of a lack of integrity" ([83], p. 199). Zuckerberg's prescriptive intentions were clear: "The days of you having a different image for your work friends or co-workers and for the other people you know are probably coming to an end pretty quickly", he suggested. Such a bald attempt to shoe-horn human subjectivity into Facebook's revenue model prompted Zimmerman [84] to suggest that "Zuckerberg must have skipped that class where Jung and Goffman were discussed". His statement also neglects a key component of the "beginner's mind" cultivated through contemplative practice, namely the realization of "the impermanent and ephemeral nature of the individual identity and indeed of all things" ([30], p. 140). In an important sense, there is no inherently existing self to be uncovered and accurately displayed in the form of a digital profile.

Given the dynamics of the privileged self within digital capitalism, Zuckerberg's statement about identity and integrity is ironic. Those who boast of having nothing to hide or of having a single transparent identity, rarely identify as racial, political or sexual minorities ([5], p. 200). In 2014, Facebook issued a formal apology in response to a backlash from LGBTQ users, many of whom saw their alternate "drag" profiles disappear as a result of the "real name" policy. The incident demonstrates that the pursuit of integrity is not solely individual, but collective, requiring a cultural, political and technological context that is responsive to the concerns of all. Yet, if we understand integrity as a state of being in which "no part of the self is split off in the unconscious so that it is inaccessible" ([51], p. 13), the achievement of individual and collective integrity is incompatible with the dynamics of market capitalism, which concentrates wealth and power into relatively few hands while externalizing risk [22]. Catalyzed by the appropriation of mindfulness practices, Silicon Valley ensconces the privileged self within "integrity bubbles", which I have defined as "limited contexts of work and family life in which a small but satisfied group enjoys an experience of harmony unavailable to others" [22]. Meanwhile, the struggle for collective integrity, that is with regard to achievement of a broader cultural commitment to justice and equality for all, is ongoing.

\section{Conclusions}

Technologies of the self disrupt existing moral ecologies, especially with regard to values like authenticity, responsibility and trust ([5], p. 198). Corporate elites are ill-equipped to address these disruptions, except in a self-serving manner, and despite noble intentions, activists, like Anonymous, tend toward similarly problematic views [5]. Media and religious scholarship are poised to fill this gap, to steer the ship of technological development in ways the preserve, rather than undermine the values that we hold collectively. To do so, it must engage critically the religiously-infused history of markets and technology and draw from those wisdom traditions that provide systematic insight into the nature of the self. 
Though the architecture of commercial media platforms leads users to believe otherwise, the self "isn't a thing or an entity; it's a process" ([6], p. 323). It is possible to construct platforms differently, such that "the subject of experience still exists but is no longer deluded about its nature" ([6], p. 324). Technologies that avoid fixation on self-image, instead creating opportunities to disengage from the process of identification with the content of one's stream of thought, may allow users to move beyond "mind wandering" to "mindfulness" ([6], pp. 349-55). Ironically, gadgets like Apple Watch and Google Glass are marketed as solutions to the problems of distraction and fragmentation endemic to digital capitalism. While design is an important element in the development of "normative technology", that is, technology that enhances, rather than undermines cultural values [85], such retail solutions ultimately leave the structural causes of collective suffering in place. Addressing the latter issue requires a "beginner's mind" in the full sense of the term, that is with regard to the very institutions and policies that govern technological development. It requires that scholars, developers and practitioners confront the "elephant in the digital room", capitalism, and envision alternate political-economic systems, regulatory policies and design philosophies ([17], p. 13).

The application of contemplative principles on an institutional level allows us to move from the current over-emphasis on personal mindfulness to what I have termed "civic mindfulness", that is the presence of institutional and cultural systems that cultivate and sustain collective attention toward, and responsiveness to, the structural sources of suffering in the body politic [3,22]. Such systems, aimed at facilitating the recognition of digital capitalism's shadow, would provide robust affordances for quality investigative journalism, corporate and political whistleblowing and nonviolent activism.

The theoretical elements for articulating this type of approach are available in political-economic theory, contemplative studies literature and scholarship on media and religion. Yet, they have not yet been integrated effectively. For example, in his application of contemplative principles to economics, Barbezat argues that mindfulness practice can help individual citizens understand their long-term self-interest so as to avoid the mistaken assumptions that led to the recent economic collapse (described in [86], p. 195). While this insight is helpful, its individualist focus overlooks the institutional role of professional journalism as a platform for supporting civic mindfulness. As McChesney and Nichols ([87], p. 106) argue, it is precisely journalism's potential to focus civic attention and spur collective action in advance of such crises that makes it "a necessary and indispensable part of our economic infrastructure". I have offered contemplative media studies as a framework for bringing these strands of thought together, with the goal of promoting "an ethically responsive and economically sustainable architecture of human flourishing" ([5], p. 208).

Future research along these lines will involve an exploration of alternative approaches to technological design, regulatory policy and institutional frameworks. Initiatives, such as Vendor Relationship Management (VRM), Customer Commons and the Identity Commons project, are aimed at moving beyond the proprietary approach to user data exploitation toward models that empower users to own, manage and set the terms of use for their personal information. Alternative organizational structures, such as the low-profit limited liability company (L3C) in the U.S., the community interest company (CIC) in Britain and various worker-owned cooperative models in the U.S. and abroad, are aimed at enhancing workplace democracy and the promotion of the public good. Similar organizational structures may likewise revitalize the institutions of professional investigative journalism, thus enhancing public 
awareness of technical development and its potential socio-economic impact. In contrast to the poisons of greed, aggression and delusion, such strategies enhance civic mindfulness and may yet yield a networked architecture that embodies the virtues of generosity, loving-kindness and wisdom.

\section{Conflicts of Interest}

The author declares no conflict of interest.

\section{References}

1. Kevin Healey. "Google-phonics, or, What is the Sound of a Thousand Tech Workers Meditating?" 2014. Available online: http://religiondispatches.org/google-phonics-or-what-is-the-sound-ofa-thousand-tech-workers-meditating (accessed on 28 July 2015).

2. Ronald E. Purser. "Clearing the Muddled Path of Traditional and Contemporary Mindfulness: A Response to Monteiro, Musten, and Compson.” Mindfulness 6 (2015): 23-45.

3. Kevin Healey. "Disrupting Wisdom 2.0: The Quest for Mindfulness in Silicon Valley and Beyond." Journal of Religion, Media, and Digital Culture, 2015, in press.

4. Kevin Healey. "Information is not Wisdom, Convergence is not Integrity: Proverbs for an Era of Digital Humanism." Explorations in Media Ecology, 2015, forthcoming.

5. Kevin Healey. "Coercion, Consent, and the Struggle for Social Media." Explorations in Media Ecology 13 (2014): 195-212.

6. Evan Thompson. Waking, Dreaming, Being: Self and Consciousness in Meditation, Neuroscience, and Philosophy. New York: Columbia University Press, 2015.

7. Carl Jung. An Introduction to Zen Buddhism. New York: Grove Weidenfeld, 1964, pp. 9-29.

8. Stewart M. Hoover. Religion in the Media Age. New York: Routledge, 2006.

9. Wade Clark Roof. Spiritual Marketplace: Baby Boomers and the Remaking of American Religion. Princeton: Princeton University Press, 1999.

10. Lynn Schofield Clark. From Angels to Aliens: Teenagers, the Media, and the Supernatural. New York: Oxford University Press, 2005.

11. Lynn Schofield Clark. Religion, Media, and the Marketplace. New Brunswick: Rutgers University Press, 2007.

12. Clifford Christians. "Review of the Ethics of Authenticity by Charles Taylor." Journal of Communication 44 (1994): 169-71.

13. Martha C. Nussbaum. Women and Human Development: The Capabilities Approach. Cambridge: Cambridge University Press, 2000.

14. Cornel West. The American Evasion of Philosophy: A Geneology of Pragmatism. Madison: The University of Wisconsin Press, 1989.

15. Gary Simpson. Critical Social Theory: Prophetic Reason, Civil Society, and Christian Imagination. Minneapolis: Fortress Press, 2002.

16. Cornel West. Democracy Matters: Winning the Fight Against Imperialism. New York: Penguin Press, 2004. 
17. Robert W. McChesney. Digital Disconnect: How Capitalism is Turning the Internet Against Democracy. New York: The New Press, 2013.

18. Paul Tillich. Theology of Culture. Edited by Robert Kimball. New York: Oxford University Press, 1964.

19. Kevin Healey. "You Are Not a Gadget: Prophetic Critique in the Age of Digital Media." In Prophetic Critique and Popular Media: Theoretical Foundations and Practical Applications. New York: Peter Lang, 2013, pp. 171-91.

20. Brett Robinson. Appletopia: Media Technology and the Religious Imagination of Steve Jobs. Waco: Baylor University Press, 2013.

21. Jamie Hubbard, and Paul Loren Swanson. Pruning the Bodhi Tree: The Storm over Critical Buddhism. Honolulu: University of Hawaii Press, 1997.

22. Kevin Healey. "Searching for Integrity: The Politics of Mindfulness in the Digital Economy." 2013. Available online: http://nomosjournal.org/2013/08/searching-for-integrity/ (accessed on 28 July 2015).

23. David R. Loy. "Why Buddhism and the West Need Each Other: On the Interdependence of Personal and Social Transformation.” Journal of Buddhist Ethics 20 (2013): 401-21.

24. Glenn Wallis, Tom Pepper, and Matthias Steingass. Cruel Theory-Sublime Practice: Toward a Reevaluation of Buddhism. Roskilde: EyeCorner Press, 2012.

25. Stephen Garner. "Theology and the New Media." In Digital Religion: Understanding Religious Practice in New Media Worlds. New York: Routledge, 2013, pp. 251-65.

26. Louise Connelly. "Virtual Buddhism: Buddhist Ritual in Second Life." In Digital Religion: Understanding Religious Practice in New Media Worlds. New York: Routledge, 2013, pp. 128-35.

27. Ronald E. Purser. "Deconstructing Lack: A Buddhist Perspective on Egocentric Organizations." Journal for Critical Organizational Inquiry 10 (2012): 17-27.

28. Daniel M. Veidlinger. "The Madhyama is the Message: Internet Affordance of Anatman and Pratitya Samutpada." In Buddhism, the Internet, and Digital Media: The Pixel in the Lotus. New York: Routledge, 2015, pp. 117-33.

29. Lawrence Lessig. Code 2.0. New York: Basic Books, 2006.

30. Rachel Wagner, and Christopher Accardo. "Buddhist Apps: Skillful Means or Dharma Dilution?" In Buddhism, the Internet, and Digital Media: The Pixel in the Lotus. New York: Routledge, 2015, pp. 134-52.

31. Jaron Lanier. You Are Not a Gadget: A Manifesto. New York: Vintage, 2011.

32. Clifford G Christians. "Technology and Triadic Theories of Mediation." In Rethinking Media, Religion and Culture. Thousand Oaks: Sage, 1997, pp. 65-84.

33. Daniel P. Barbezat, and Mirabai Bush. Contemplative Practices in Higher Education : Powerful Methods to Transform Teaching and Learning. San Francisco: Jossey-Bass, 2014.

34. Edward W. Sarath. Improvisation, Creativity, and Consciousness:Jazz as an Integral Template for Music, Education, and Society. Albany: State University of New York Press, 2013.

35. Olen Gunnlaugson, Edward W. Sarath, and Heesoon Bai. "An Introduction to Contemplative Learning and Inquiry across Disciplines." In Contemplative Learning and Inquiry Across Disciplines. Albany: SUNY Press, 2014, pp. 1-11. 
36. Jon Kabat-Zinn. Wherever You Go, There You Are. New York: Hyperion,1994.

37. Rupert Gethin. "On some definitions of mindfulness." Contemporary Buddhism 12 (201): 263-79.

38. Scott R. Bishop, Mark Lau, Shauna Shapiro, Linda Carlson, Nicole D. Anderson, James Carmody, Zindel V. Segal, Susan Abbey, Michael Speca, Drew Velting, and et al. "Mindfulness: A proposed operational definition.” Clinical Psychology: Science and Practice 11 (2004): 230-41.

39. Mark Williams, and Jon Kabat-Zinn. "Mindfulness: Diverse Perspectives on its Meaning, Origins, and Multiple Applications at the Intersection of Science and Dharma." In Mindfulness: Diverse Perspectives on its Meaning, Origins and Applications. New York: Routledge, 2013, pp. 1-18.

40. Brazier, David. "It Needs Saying." 2015. Available online: http://www.tricycle.com/blog/itneeds-saying (accessed on 30 May 2015).

41. Jeff Wilson. Mindful America: The Mutual Transformation of Buddhist Meditation and American Culture. New York: Oxford University Press, 2014.

42. Nalin Swaris. The Buddha's Way to Human Liberation: A Socio-Historical Approach. Navayana: New Delhi, 2011.

43. David Brazier. The New Buddhism; New Year: Palgrave, 2002.

44. Kevin Healey. "Contemplative Media Studies." Paper presented at Association for Contemplative Mind in Higher Education, Amherst, MA, USA, 9 November 2013.

45. Abraham H. Maslow. The Farther Reaches of Human Nature. New Year: Viking Press, 1971.

46. Tom Bruneau. "An Ecology of Natural Mindlessness: Solitude, Silence, and Transcendental Consciousness." Explorations in Media Ecology 10 (2011): 55-73.

47. Kevin Healey. "Solitude and Presence: Photo Reflections on Natural and Digital Ecologies." 2014. Available online: http://nomosjournal.org/2014/02/solitude-and-presence/ (accessed on 28 July 2015).

48. Clifford G. Christians. "Cultural Continuity as an Ethical Imperative." Qualitative Inquiry 13 (2007): 437-44.

49. Zajonc, Arthur. "Contemplative Pedagogy in Higher Education: Toward a More Reflective Academy." In Contemplative Learning and Inquiry Across Disciplines. Albany: SUNY Press, 2014, pp. 15-29.

50. Charles Hampden-Turner. Maps of the Mind: Charts and Concepts of the Mind and its Labyrinths. New York: Collier Books, 1981.

51. John Beebe. "The Place of Integrity in Spirituality." In The Psychology of Mature Spirituality: Integrity, Wisdom, Transcendence. Routledge: Pennsylvania, 2000, pp. 11-20.

52. Gordon B. Hinckley. "Standing for Something." Journal of Philosophy 92 (1995): 235-60.

53. Chris Matyszczyk. "Zuckerberg: I know that people don't want privacy." 2010. Available online: http://www.cnet.com/news/zuckerberg-i-know-that-people-dont-want-privacy/ (accessed on 28 July 2015).

54. Gregory Price Grieve. "A Virtual Bodhi Tree: Untangling the Cultural Context and Historical Genealogy of Digital Buddhism.” In Buddhism, the Internet, and Digital Media: The Pixel in the Lotus. London: Routledge, 2015, pp. 93-113.

55. Melissa Young, and Mark Dworkin, Shift Change. Oley: Bullfrog Films, 2013. DVD video, $190 \mathrm{~min}$. 
56. Robert W. McChesney. Rich Media, Poor Democracy. Urbana-Champaign: University of Illinois Press, 1999.

57. Frank Lambert. The Founding Fathers and the Place of Religion in America. Princeton: Princeton University Press, 2006.

58. Adam Smith. An Inquiry into the Nature and Causes of the Wealth of Nations. Edited by Edwin Cannan. Chicago: University of Chicago Press, 1977.

59. George M. Marsden. Fundamentalism and American Culture: The Shaping of Twentieth-Century Evangelicalism 1870-1925. Oxford: Oxford University Press, 1980.

60. R. Laurence Moore. Selling God: American Religion in the Marketplace of Culture. New York: Oxford University Press, 1994.

61. Quentin J. Schultze. Christianity and the Mass Media in America: Toward a Democratic Accomodation. East Lansing: Michigan State University Press, 2003.

62. John Dewey. Individualism Old and New. New York: Prometheus Books, 1999.

63. Stuart Ewen. PR! A Social History of Spin. New York: Basic Books, 1996.

64. Kevin M. Kruse. One Nation Under God: How Corporate America Invented Christian America. New York: Basic Books, 2015.

65. Fred Turner. From Counterculture to Cyberculture: Stewart Brand, the Whole Earth Network, and the Rise of Digital Utopianism. Chicago: University of Chicago Press 2006.

66. Harry S. Stout. The Divine Dramatist: George Whitefield and the Rise of Modern Evangelicalism. Grand Rapids: W.B. Eerdmans, 1991.

67. Clements, Warren. "Futuristic documentary is both exhilarating and sad." 2011. Available online: http://www.theglobeandmail.com/arts/futuristic-documentary-is-both-exhilarating-and-sad/ article622834/ (accessed on 28 July 2015).

68. Robert M. Geraci. Apocalyptic AI: Visions of Heaven in Robotics, Artificial Intelligence, and Virtual Reality. New York: Oxford University Press, 2010.

69. Siva Vaidhyanathan. "Berkman Center: Vaidhyanathan on the Googlization of Everything." 2011. Available online: https://cyber.law.harvard.edu/events/2011/02/vaidhyanathan (accessed on 28 July 2015).

70. Kevin Healey. "Processing is not Judgment, Storage is not Memory: Media Beyond the Catechism of Silicon Valley." International Journal of Communication, 2015, submitted.

71. Josh Lauer. The Good Consumer: A History of Credit Surveillance and Financial Identity in America. New York: Columbia University Press, forthcoming.

72. Scheiber, Noam. "The Brutal Ageism of Tech." New Republic, 2014. Available online: http://www.newrepublic.com/article/117088/silicons-valleys-brutal-ageism (accessed on 28 July 2015).

73. Vargas, Jose Antonio. "The Face of Facebook." 2010. Available online: http://www.newyorker. com/magazine/2010/09/20/the-face-of-facebook (accessed on 28 July 2015).

74. Jenny Chan. "A suicide survivor: the life of a Chinese worker." New Technology, Work and Employment 28 (2013): 84-99. 
75. Kevin Healey. "On Whistleblowing, MLK, Jr., and the Politics of Resistance in the Digital Age." 2014. Available online: http://religiondispatches.org/on-whistleblowing-mlk-jr-and-the-politicsof-resistance-in-the-digital-age/ (accessed on 28 July 2015).

76. Nicholas Carr. "More present than the present." 2009. Available online: http://www.roughtype. com/?p=1235 (acccessed on 28 July 2015).

77. Theresa Sauter. "What's on your mind? Writing on Facebook as a tool for self-formation." New Media and Society 16 (2014): 823-39.

78. Shatzer, Jacob. "Virtue, Vice, and Virtual Worlds: A Theological Perspective on Moral Formation." Journal of Religion, Media, and Digital Culture 1 (2012): 1-34.

79. Elliot T. Panek, Yioryos Nardis, and Sara Konrath. "Mirror or Megaphone?: How relationships between narcissism and social networking site use differ on Facebook and Twitter." Computers in Human Behavior 29 (2013): 2004-12.

80. Brett Lunceford. "The New Pornographers: Legal and Ethical Considerations of Sexting." In The Ethics of Emerging Media: Information, Social Norms, and New Media Technology. New York: Continuum, 2011, pp. 99-118.

81. Sabine Trepte, and Leonard Reinecke. "The Social Web as a Shelter for Privacy and Authentic Living.” In Privacy Online. Berlin Heidelberg: Springer-Verlag, 2011, pp. 61-73.

82. Martin Beck. “Zuckerberg Dislikes The Idea Of A Facebook 'Dislike' Button.” 2014. Available online: http://marketingland.com/zuckerberg-dislikes-110958 (accessed on 28 July 2015).

83. David Kirkpatrick. The Facebook Effect: The Inside Story of the Company That is Connecting the World. New York: Simon and Schuster, 2010.

84. Michael Zimmerman. "Facebook's Zuckerberg: 'Having two identities for yourself is an example of a lack of integrity'." 2010. Available online: http://www.michaelzimmer.org/2010/05/14/ facebooks-zuckerberg-having-two-identities-for-yourself-is-an-example-of-a-lack-of-integrity/ (accessed on 28 July 2015).

85. Clifford Christians. "A theory of Normative Technology." In Technological Transformation: Contextual and Conceptual Implications. Boston: Kluwer Academic Publishers, 2013, pp. 123-40.

86. Mirabai Bush. "Mindfulness in Higher Education.” Contemporary Buddhism 12 (2011): 183-97.

87. Robert W. McChesney, and John Nichols. The Life and Death of American Journalism: The Media Revolution that Will Begin the World Again. Philadelphia: Nation Books, 2010.

(c) 2015 by the author; licensee MDPI, Basel, Switzerland. This article is an open access article distributed under the terms and conditions of the Creative Commons Attribution license (http://creativecommons.org/licenses/by/4.0/). 